\title{
Ultrasound Imaging of Postpartum Hemorrhage
}

\author{
${ }^{1}$ Prachi Kasar, ${ }^{2}$ Wiku Andonotopo, ${ }^{3}$ Sanja Kupesic Plavsic
}

\begin{abstract}
The etiology of postpartum hemorrhage $(\mathrm{PPH})$ is diverse and management depends on identifying the cause and tailoring treatment appropriately. The major causes of PPH are uterine atony, endometritis, retained placental tissue, placental abnormalities, i.e. placenta accreta, increta and percreta, subinvolution of the placental implantation site, arteriovenous malformation (AVM), lower genital tract trauma, uterine abnormalities, bleeding disorders, coagulopathies and use of anticoagulants. Use of imaging modalities (i.e. ultrasound scanning and color and pulsed Doppler) at an early stage in the search for the etiology of PPH helps to decrease morbidity and mortality.

This article reviews the differential diagnoses for bleeding in the postpartum period and assesses the role of ultrasound in the diagnosis and treatment of postpartum bleeding. By using illustrative images, the reader will be able to correlate findings on B-mode, color Doppler and 3D ultrasound in diagnosis and treatment of postpartum bleeding. It is important to be aware of the appearance of normal postpartum uterus to avoid misdiagnosis.
\end{abstract}

Keywords: AV malformation, B-mode ultrasound, Color Doppler ultrasound, Endometritis, Normal puerperium, Placenta accreta, Postpartum bleeding.

How to cite this article: Kasar P, Andonotopo W, Kupesic Plavsic S. Ultrasound Imaging of Postpartum Hemorrhage. Donald School J Ultrasound Obstet Gynecol 2015;9(2):175-187.

Source of support: Nil

Conflict of interest: None

\section{INTRODUCTION}

Postpartum hemorrhage (PPH), the loss of more than $500 \mathrm{ml}$ of blood after a vaginal delivery or $1,000 \mathrm{ml}$ or more after a cesarean section (C-section), is the leading

\footnotetext{
${ }^{1}$ Medical Assistant (American Red Cross Volunteer),

${ }^{2}$ Consultant and Specialist, ${ }^{3}$ Assistant Academic Dean

${ }^{1}$ Department of Obstetrics and Gynecology, William Beaumont Army Medical Center, EI Paso, Texas, USA

${ }^{2}$ Department of Obstetrics and Gynecology, Tangerang General Hospital, University of Indonesia, Banten, Indonesia

${ }^{3}$ Department of Obstetrics and Gynecology, Paul L Foster School of Medicine, Texas Tech University Health Sciences Center EI Paso, Texas, USA

Corresponding Author: Sanja Kupesic Plavsic, Assistant Academic Dean and Professor, Department of Obstetrics and Gynecology, Paul L Foster School of Medicine, Texas Tech University Health Sciences Center, EI Paso 79905, Texas, USA, Phone: (915) 215 5065, e-mail: sanja.kupesic@ttuhsc.edu
}

cause of maternal death worldwide. American College of Obstetricians and Gynecologists (ACOG) defines PPH as blood loss, which decreases the hematocrit level by $10 \%$ between admission and the postpartum period, or the need for transfusion after delivery secondary to blood loss. ${ }^{1}$ More than 140,000 women die annually as a result of PPH, which corresponds to approximately one maternal death every 4 minutes. ${ }^{1}$ Even in developed or higher-income countries such as the United States, obstetric and PPH accounts for approximately $8 \%$ of maternal deaths and is consistently among the top 3 causes for direct maternal mortality. ${ }^{2}$ Postpartum hemorrhage is a nightmare even to the present day obstetrician as it is sudden, often unpredictable and the consequences may be catastrophic. ${ }^{3}$ Unfortunately, the estimation of blood loss that is routinely evaluated by the clinicians' visual inspection following delivery is subjective, typically inaccurate and underreported.

There is an unavoidable blood loss during parturition. This blood loss is not larger because of two mechanisms that maintain vascular integrity following placental separation. The first involves constriction of uterine blood vessels in the placental bed by myometrial fibers. The second is an intact coagulation system. A disruption of either or both of these mechanisms will result in postpartum bleeding. ${ }^{4}$

Primary PPH is traditionally defined as the loss of more than $500 \mathrm{ml}$ of blood from the genital tract in the first 24 hours after delivery or any loss even if less than $500 \mathrm{ml}$, if associated with hemodynamic changes in the mother. If the blood loss occurs between 24 hours and 6 weeks after delivery, it is defined as secondary PPH. ${ }^{1,4}$

The main causes of primary PPH are uterine atony, retained placenta, lower genital tract trauma along with coagulopathy and clotting disorders, which compound the problem. Uterine inversion and uterine rupture are less common causes. ${ }^{3}$ The main predisposing factors for secondary PPH are retained placental fragments and uterine infection. ${ }^{5}$

The diagnosis of postpartum bleeding is usually obvious and in majority of the cases the etiology of the problem is also apparent. Excessive bleeding may occur before delivery of the placenta, following delivery of the placenta or late in the postpartum period. The etiology and the management of the bleeding will be different depending on when the bleeding occurs. ${ }^{4}$ The primary 
aim of the obstetrician in the management of PPH should be prediction and prevention. ${ }^{3}$

\section{CASE REPORTS}

\section{Case 1}

A 30-year-old G2P2 delivered a 7-lb healthy male infant 7 days ago. In early postpartum period, she has experienced vaginal bleeding with passage of clots. She had an uncomplicated pregnancy with spontaneous onset of labor and spontaneous rupture of membranes at $5 \mathrm{~cm}$ dilation. She had no episiotomy and had no perineal lacerations. The placenta spontaneously delivered 5 minutes after delivery of the infant. The placenta was normal in appearance and intact. Her blood pressure is $110 / 70 \mathrm{~mm} \mathrm{Hg}$, pulse is $88 / \mathrm{min}$, respirations are $14 / \mathrm{min}$. Abdominal examination shows a firm uterus undergoing involution. Figure 1 illustrates ultrasound findings of the patient 1 week after the vaginal delivery.

\section{Case 2}

A 28-year-old G2P2 presented at 39 weeks with confirmed premature rupture of membranes. She underwent a C-section due to arrest of cervical dilation. Seven days after delivery, she presented with abnormal uterine bleeding, pelvic and lower abdominal pain and fever. Her vital signs show a temperature of $100.4^{\circ} \mathrm{F}\left(38^{\circ} \mathrm{C}\right)$; pulse 90/min; blood pressure 110/70 $\mathrm{mm} \mathrm{Hg}$; and respirations $18 / \mathrm{min}$. On examination, her lungs are clear, abdomen is soft. Pelvic examination reveals foul smelling lochia and tender uterus. Complete blood count (CBC) reveals leukocytosis with a left shift; hemoglobin $10 \mathrm{~g} / \mathrm{dl}$ and hematocrit 30. Endometrial and blood cultures are obtained and pending. Her ultrasound and Doppler findings are demonstrated in Figures 2 and 3.

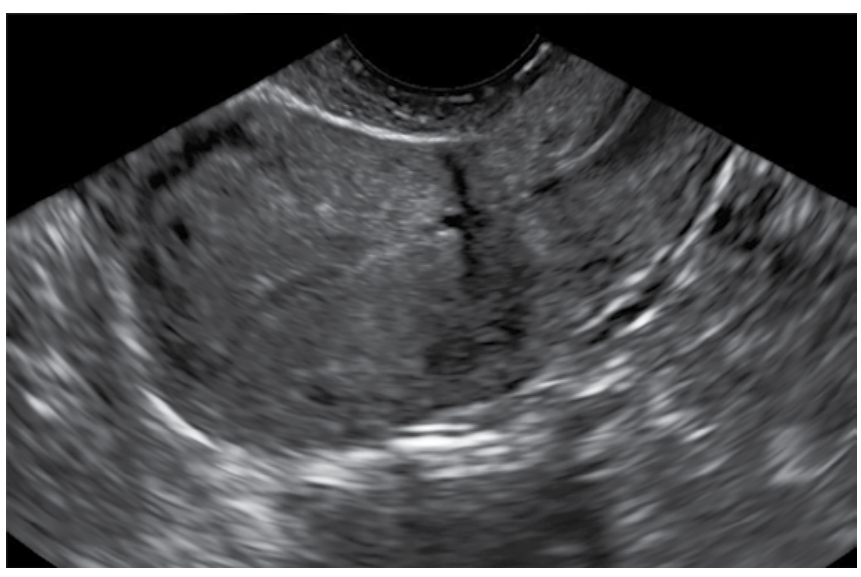

Fig. 1: Sagittal image of the uterus demonstrates a small amount of sonolucent fluid within the endometrial cavity. The endometrial cavity appears normal, with no evidence of retained products of conception. There is minimal free fluid in the pelvis. The visualized myometrium is homogenous in appearance

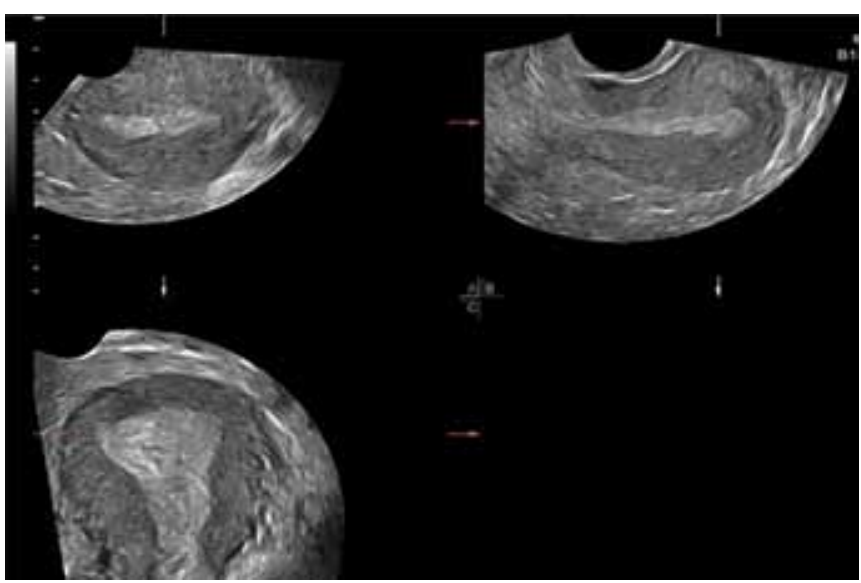

Fig. 2: Three-dimensional (multiplanar) ultrasound of the thickened and hyperechogenic endometrium

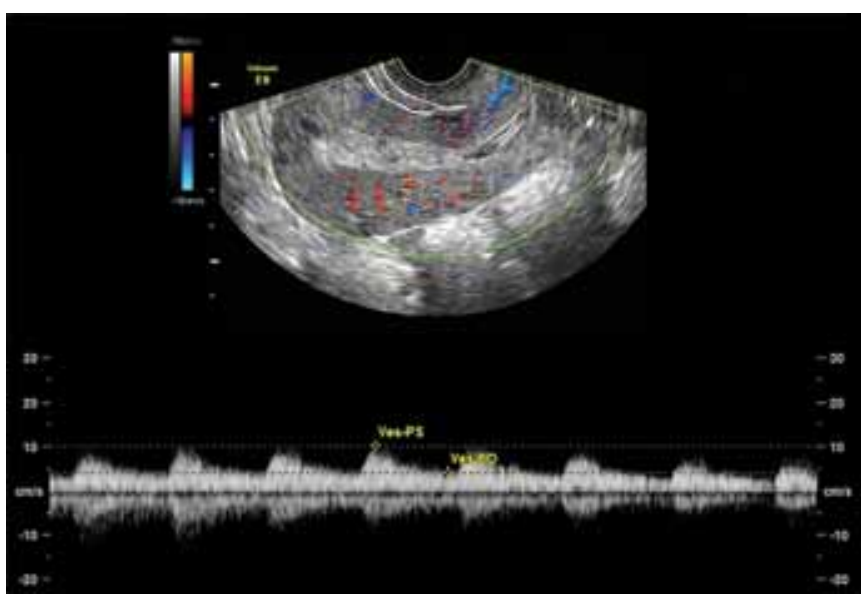

Fig. 3: Color Doppler image of the same patient. Color Doppler reveals moderate to high vascular impedance, with RI of 0.59

\section{Case 3}

A 23-year-old G1P1 delivered a 35-week infant vaginally 4 weeks ago. She presents to the emergency room (ER) with uterine bleeding and anemia (hemoglobin $9 \mathrm{~g} / \mathrm{dL}$, hematocrit 28). Her vital signs show a temperature of $98.2^{\circ} \mathrm{F}$ $\left(36.8^{\circ} \mathrm{C}\right)$; pulse $104 / \mathrm{min}$; blood pressure $100 / 55 \mathrm{~mm} \mathrm{Hg}$ and respirations $20 / \mathrm{min}$. On examination, her lungs are clear, cardiac exam is normal, abdomen is soft, uterine fundus is firm and tender, with no evidence of suprapubic tenderness. Pelvic ultrasound revealed enlarged uterus with heterogeneous mass in the uterine cavity (Fig. 4). Color and pulsed Doppler images of the same patient are shown in Figures 5 and 6.

\section{Case 4}

A 36-year-old G1P1 delivered 35-week twins by C-section. Nineteen days postoperatively, she was readmitted for sudden and profuse vaginal bleeding, which settled spontaneously. A presumptive diagnosis of endometritis with possible retained products of conception was made and treatment in the form of intravenous antibiotics was 


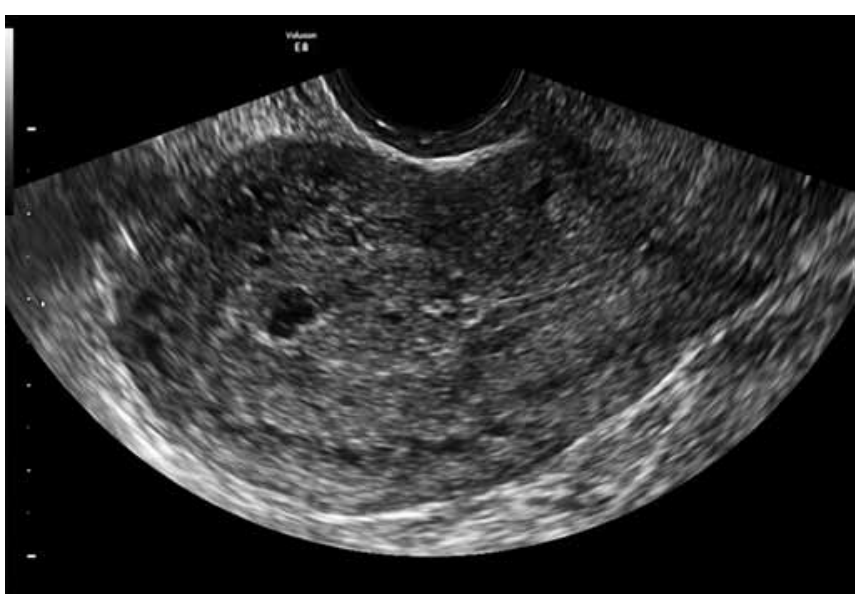

Fig. 4: B mode illustrates heterogeneous intracavitary lesion

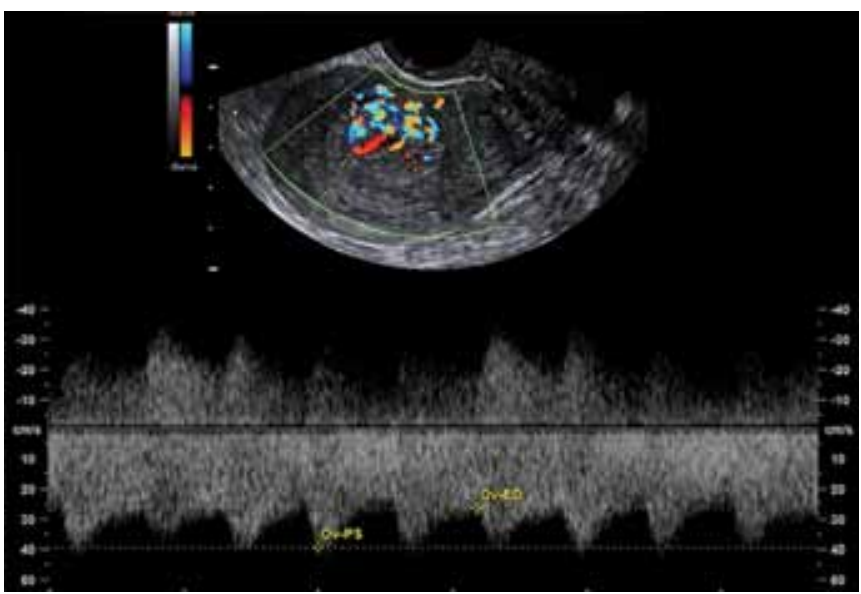

Fig. 6: Pulsed Doppler waveform analysis of the same patient. Note low vascular impedance blood flow signals with RI of 0.33

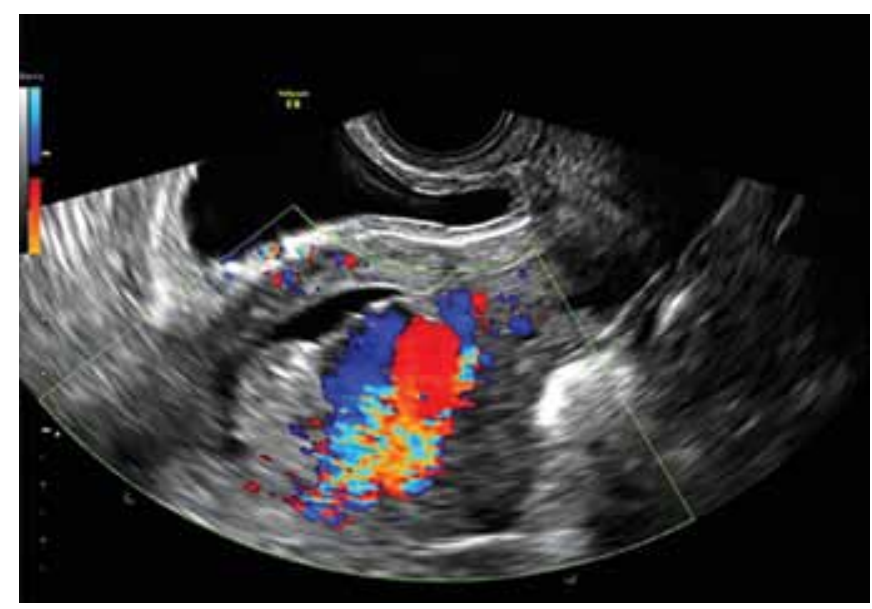

Fig. 8: Color Doppler image of the same patient

instituted. Three days later, the patient is seen in the ER because of torrential bleeding which led to hypotension and warranted blood transfusion. Clinical examination revealed a soft and nontender abdomen. Speculum examination revealed heavy vaginal bleeding and blood clots in the vagina. The uterus was anteverted,

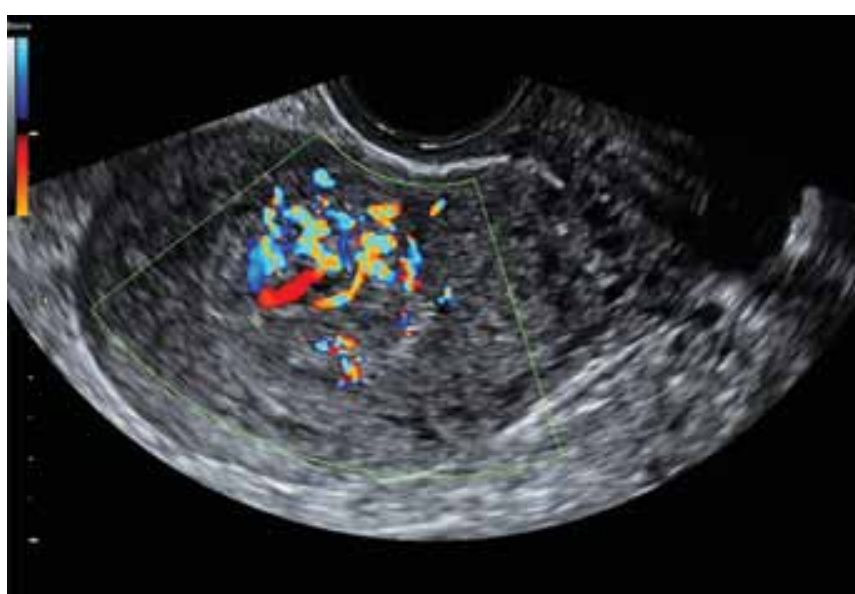

Fig. 5: Color Doppler reveals hypervascular intracavitary lesion

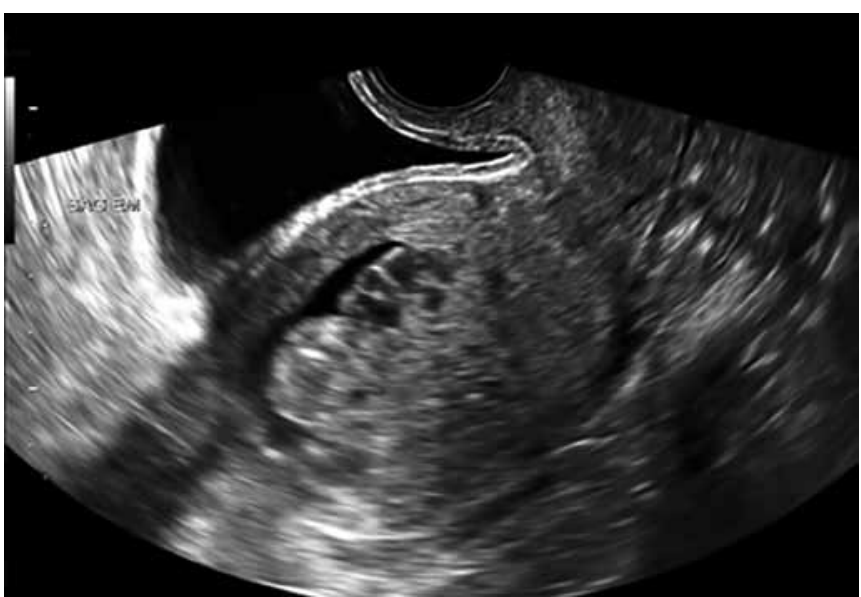

Fig. 7: Heterogeneous uterine mass, with prominent cystic lesions within the superficial portion of the myometrium

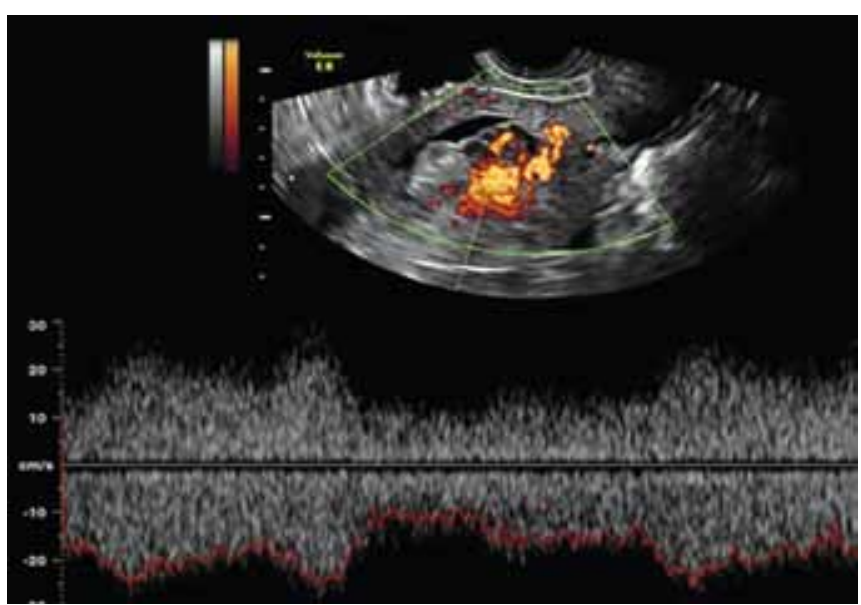

Fig. 9: Pulsed Doppler waveform analysis of the same patient. Note mixed arterial and venous flow

slightly enlarged and non-tender. Investigations included $\beta$-hCG and coagulation studies. $\beta$-hCG was negative and coagulation studies were within the normal limits. Her B mode ultrasound, color Doppler, pulsed Doppler and 3D color Doppler imaging findings are illustrated in Figures 7 to 10 . 


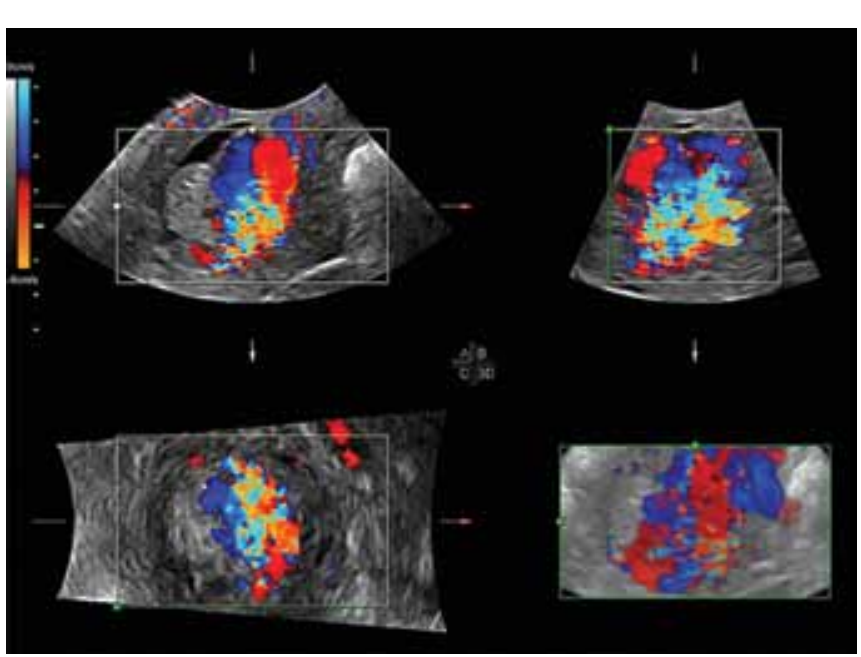

Fig. 10: Three-dimensional color Doppler image of the same patient

\section{Case 5}

A 36-year-old patient, G5P3A2 was admitted at 37 weeks' gestation to the obstetric preoperative care for an elective cesarean delivery. Her obstetrical history is significant for two missed abortions, for which dilatation and curettage was performed, and two C-sections. The patient had experienced vaginal bleeding in the second trimester. Her last ultrasound was performed at 35 weeks 2 days. Her $B$ mode ultrasound and color Doppler imaging findings are illustrated in Figures 11 and 12.

\section{DISCUSSION}

\section{Case 1: Normal Puerperium}

The puerperium begins after delivery and lasts until 6 weeks postpartum. Normal puerperium involves reversal of the changes of pregnancy into a prepregnancy state. This is a period of extraordinary physiological and psychological changes. ${ }^{6}$ The main characteristic of the

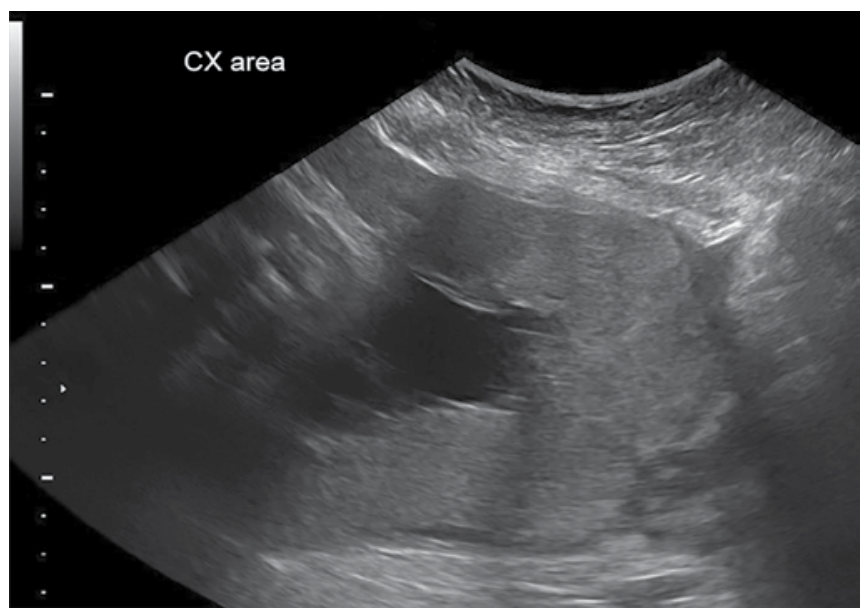

Fig. 11: Transvaginal B mode ultrasound of the patient presented in case study 5 . Note that placenta is covering the internal cervical os. There is no clear demarcation between the placenta and the uterine wall puerperium is the involution of the uterus, an extremely dynamic process of physiological transformation of the uterus involving the myometrium, decidua and uterine arteries. $^{7}$

At term, the normal volume of blood flow throughout the placenta is $500-800 \mathrm{ml}$ per minute, which serves to fulfill the perfusion demands of the low-resistance uteroplacental unit and to provide a reserve for the blood loss that occurs at delivery. At placental separation, this has to be arrested within seconds, otherwise serious hemorrhage may occur. Following delivery of the fetus, uterine contractions continue and the placenta is sheared from the underlying endometrium. This separation primarily occurs by a reduction in the surface area of the placental site as the uterus shrinks. This decrease is caused by myometrial retraction, which is a unique characteristic of the uterine muscle to maintain its shortened length following each successive contraction. In this way, the placenta is undermined, detached and propelled into the lower uterine segment.

The second mechanism of separation is through hematoma formation due to venous occlusion and vascular rupture in the placental bed caused by uterine contractions. As the placenta detaches, the spiral arteries are exposed in the placental bed. The vessels supplying the placental bed traverse a latticework of crisscrossing muscle bundles that occlude and kink-off the vessels as they contract and retract following expulsion of the placenta. This arrangement of muscle bundles has been referred to as the 'living ligatures' or 'physiologic sutures' of the uterus. ${ }^{8}$

Following separation, the strong uterine contractions bring the uterine walls into apposition so that further pressure is exerted on the placental site. There is transitory increased activation of the coagulation and the fibrinolytic systems around the placental site, so clot

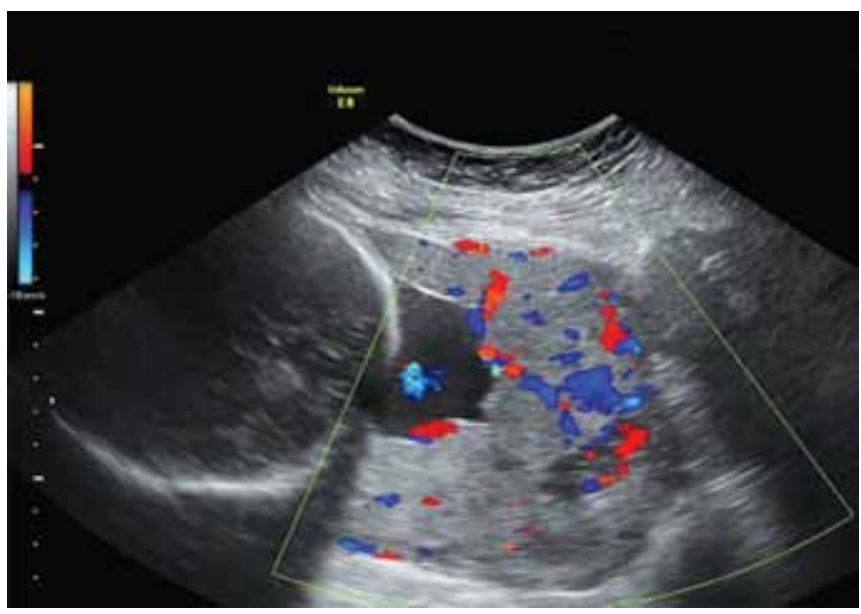

Fig. 12: Color Doppler image of the same patient. Color Doppler ultrasound image helps confirm that the hypoechoic spaces noticed on B mode ultrasound represent placental lacunae 
formation in the torn vessels is intensified. Following separation, the placental site is rapidly covered by a fibrin mesh. ${ }^{9}$ Immediately after placental expulsion, uterine fundus is palpable at or near the level of the maternal umbilicus. Immediately after delivery, a large amount of approximately $600 \mathrm{ml} / \mathrm{min}$ of blood flows from the uterus until the contraction phase occurs.

Clinical signs and symptoms in the patient provide an idea of the amount of blood loss and the patient's ability to cope with such loss. Loss of 10 to $15 \%$ of the blood volume generally does not alter the blood pressure but will cause a mild tachycardia and postural hypotension. There will be vasoconstriction of the skin and skeletal muscle vascular bed, with the patient looking pale, feeling weak and her skin cold to touch. ${ }^{3}$ The patient in this case is normotensive, with an intact placenta and no lower genital tract trauma.

Active management of the third stage of labor with administration of uterotonics before the placenta is delivered (oxytocin still being the agent of choice), early clamping and cutting of the umbilical cord, and traction on the umbilical cord have proven to reduce blood loss and decrease the rate of PPH. Fundal massage helps stimulate the atonic uterus to contract and can easily be started while other interventions are being prepared.

Ultrasound appearances of the uterus and uterine cavity change throughout the puerperium in a unique way. The uterine dimensions diminish progressively and substantially during the puerperium so that the uterus, weighing more than $1 \mathrm{~kg}$ soon after delivery, weighs only $80 \mathrm{gm}$ at the end of the puerperium. In the early puerperium between days 1 and 3, the uterus is most often retroverted and has an angulated form. The uterine cavity is empty and the decidua appears as a thin white line from the fundus to the level of the internal cervical os (Fig. 1). In the middle part of the puerperium between days 7 and 14, the uterus is anteverted and oval shaped, with abundant fluid or mixed echo pattern seen in the whole cavity. This finding reflects a normal healing process of the placenta. In late puerperium, between days 28 and 56, the uterus is considerably decreased in size; the uterine cavity is empty and on ultrasound appears as a thin white line. Minor amounts of endometrial fluid or a mixed echo pattern are rare findings during the late puerperium.

The uterine artery Doppler flow pattern shows an increase in resistance indices beginning by the 2 nd postpartum day and continuing for the next 6 weeks.

\section{Cases 2 and 3: Endometritis with and without Retained Products of Conception}

Secondary PPH is vaginal bleeding between 48 hours and 6 weeks after delivery, usually between 6 and 14 days, and typically on the 10th postpartum day. In secondary $\mathrm{PPH}$, the possibility of sepsis must always be considered. ${ }^{17}$

Postpartum endometritis is a fairly common clinical condition affecting 2 to $5 \%$ women following delivery. It is a polymicrobial ascending infection of organisms that constitute the normal vaginal flora. ${ }^{4}$ Sepsis and $\mathrm{PPH}$ are linked by common predisposing factors, especially considering that secondary PPH can follow infection of retained placenta or endometrium. ${ }^{19}$ In both cases, the underlying mechanism is a subinvolution of the placental site. The presence of retained tissue and large open area of the placental site offer favorable conditions for sepsis to develop.

The route of delivery is the single most important risk factor for development of postpartum endometritis. ${ }^{10}$ Postpartum endometritis has a 2 to $3 \%$ incidence following a vaginal delivery, whereas the incidence following C-section is 6 to $10 \%$. These incidences increase significantly in the face of prolonged rupture of membranes or chorioamnionitis to 13 and $85 \%$ for vaginal delivery and C-section respectively. The other known risk factors for endometritis include young age, low socioeconomic status, prolonged labor, multiple vaginal examinations, placement of an intrauterine catheter, preexisting infection or colonization of the lower genital tract, twin delivery and manual removal of the placenta. Whenever the obstetrician is faced with postpartum bleeding accompanied by signs of endometritis, the most important question is whether placental tissue has been retained in the cavity or not.

Endometritis is usually a clinical diagnosis. Patients may generally be well with a small amount of bleeding or may present with postpartum fever and significant bleeding with hemorrhagic or septic shock. Uterus may be subinvoluted and tender to touch. The cervical os may be open if there are retained products of conception or blood within the uterine cavity with or without foulsmelling vaginal discharge. There may be signs of pelvic or generalized peritonitis. ${ }^{11}$ If the bleeding has been continuous since delivery, it is more suggestive of retained products of conception and if the bleeding has started again, it indicates an infection. Complications of postpartum endometritis include pelvic abscess, thromboembolism, septicemia and septic shock leading to DIC.

Identifying a septic patient in postpartum period is very important. High-dose intravenous antibiotics should be started as soon as possible without delay with prior blood cultures, cervical and vaginal swabs taken. If there are RPOC, surgical evacuation of the uterine cavity should be done. The postpartum uterus is very soft and utmost care should be taken when 
undertaking this procedure, as there is a potential risk of perforation of the uterus. In addition, care should be taken to avoid excessive curettage, as it will increase the risk of Ashermann's syndrome/intrauterine adhesions. If there are no retained products of conception seen, management is primarily to control the bleeding. If bleeding is not significant, intravenous antibiotics and sometimes intravenous tranexamic acid would be sufficient to control the infection and bleeding. If bleeding is significant, procedures like balloon tamponade of the uterus or uterine artery embolization with interventional radiology may be lifesaving. In exceptional circumstances, internal iliac ligation or postpartum hysterectomy may be required. ${ }^{11}$

It is clear that the most important measure for preventing the onset of postpartum endometritis is avoiding the abdominal route of delivery. Unfortunately, this measure seems to be unrealistic in view of the increasing incidence of cesarean deliveries. ${ }^{4}$ Administration of prophylactic antibiotics at the time of cesarean delivery, difficult operative deliveries and for manual removal of placenta is an important measure for preventing postpartum endometritis. The physician should ensure that the uterus is empty at the time of delivery. If there is any doubt of completeness of the placenta or membranes an examination under anesthesia should be performed. ${ }^{12}$

If the clinical picture is equivocal, or if there is concern for more complicated infection, there is a role for imaging. The use of ultrasound in patients with clinical signs of postpartum endometritis is primarily to exclude the presence of retained placental tissue in the uterine cavity. Endometrial mass with some fluid along the margins is specific of RPOC. Color Doppler imaging assists in detection of the presence or absence of the low within the uterine cavity. Absent flow is suggestive of hemorrhagic material or clots in the uterus. Nonviable placental tissue within the uterus also demonstrates absence of blood flow signals. The presence of any vascularity within the endometrium has a high likelihood of representing RPOC (Figs 13A and B). Increased perfusion within the adjacent myometrium may be associated with hypertrophied peritrophoblastic vessels which communicate via areas of necrosis in the retained placenta.

In the vast majority of cases of isolated endometritis, ultrasound findings are normal and have no pathognomonic ultrasound image. Alternatively, echogenic foci, gas and fluid in the endometrial canal may be seen with endometritis, but are also seen with some frequency in asymptomatic postpartum patients. The presence of endometrial gas in the clinical setting of postpartum fever nonetheless increases the likelihood that endometritis is present. Endometritis may also appear as diffuse increased endometrial vascularity that does not exhibit low resistance flow as expected with retained products (Fig. 3). Moreover, clinical improvement following conservative treatment with antibiotics and uterotonic medication speaks against the presence of retained products. In conclusion, ultrasound images in endometritis are not substantially different from those after an uncomplicated delivery.
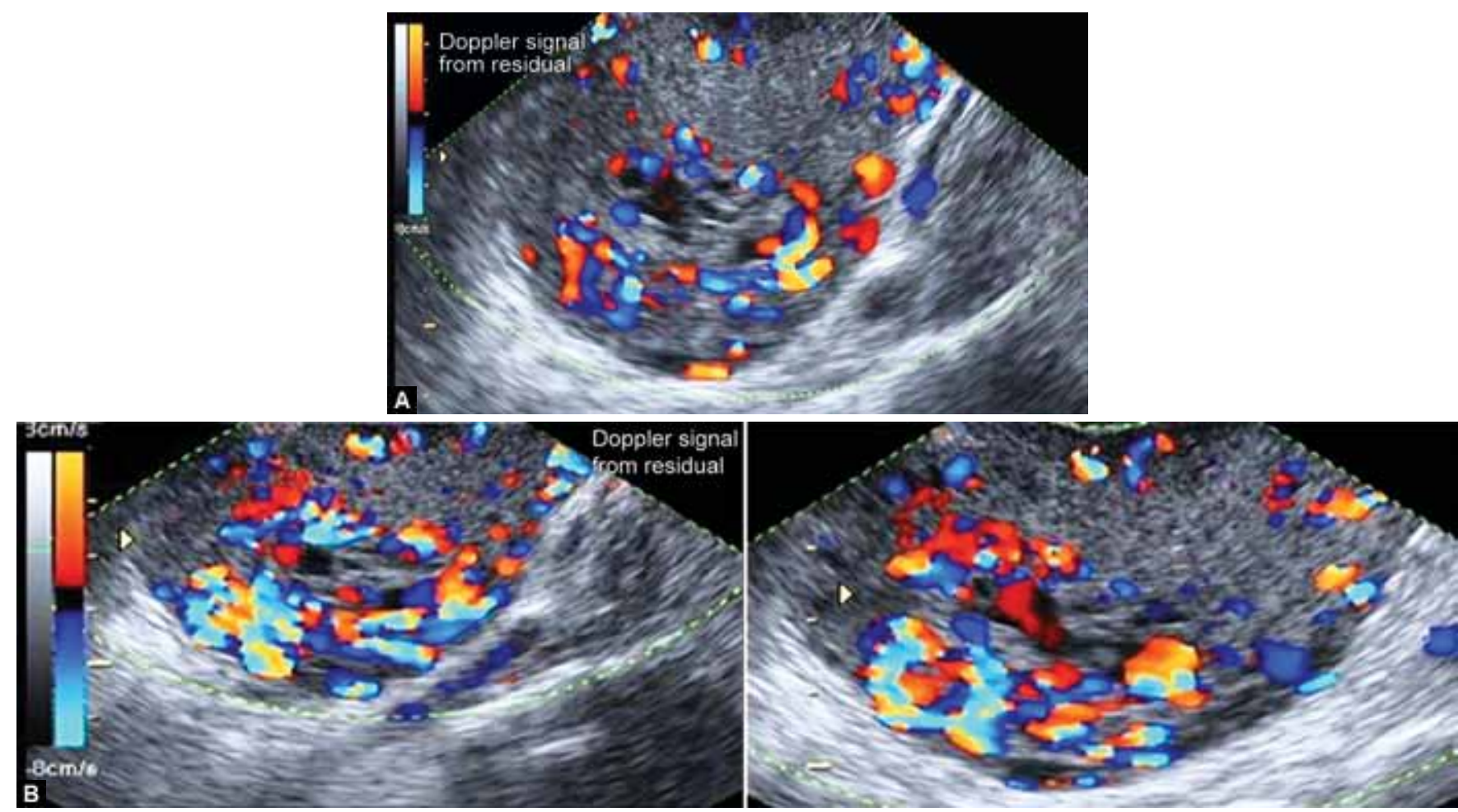

Figs 13A and B: Color Doppler image of highly vascular area in the endometrium, typical for residual products of conception, (B) prominent vascularity is noted within the adjacent myometrium 
Computed tomography (CT) is used to evaluate for extension of endometritis beyond the uterus, particularly if there is concern for abscess or septic thrombophlebitis. Computed tomography better demonstrates extrauterine fluid collections and may guide therapeutic drainage of pelvic abscesses. Sepsis can be prevented by adopting universal aseptic precautions during delivery and ensuring complete delivery of the placenta.

\section{Case 4: Arteriovenous Malformation}

Arteriovenous malformations (AVMs) arise by definition from an abnormal communication between an artery and a vein with localized proliferation of each vessel with interconnecting fistulae. Intertwining these muscular vessels are many thin-walled capillary-type vessels. This fact explains some of the variations seen in Doppler waveform profiles from the various reported cases of uterine AVMs.

Pregnancy appears to have an important role in the pathogenesis of uterine AVMs. It is postulated that these malformations may arise when venous sinuses become incorporated in scars within the myometrium after necrosis of the chorionic villi. ${ }^{13}$ There is also speculation that many reported AVMs are in fact subinvolution of the placental bed and may share a similar etiology related to delayed transition of uteroplacental vessels to normal uterine spiral arteries. ${ }^{14}$ It has also been hypothesized that some viable trophoblast cells may remain in 'placental polyps' and vessels below the retained products of conception (RPOC) may show persistent dilation. This is also perhaps why there is an association with trophoblastic disease, in particular following treatment with chemotherapeutic agents.

Uterine AVMs are divided into congenital and acquired subtypes..$^{15}$ True or congenital AVMs are rare errors of morphogenesis, which do not regress spontaneously. Also, in congenital AVMs, the lesions may be multiple involving other organs of the body. On angiography, acquired AVMs have one or two uterine artery feeding vessels and early filling of draining veins; as by definition, there is an absent capillary bed and an abnormal communication between the arteries and veins. Acquired AVMs lack the characteristic nidus of tangled vessels between the feeding arteries and draining veins seen in congenital AVMs. ${ }^{14}$ Acquired uterine AVMs are usually traumatic and may be related to dilation and curettage (D \& C), therapeutic abortion, uterine surgery, or direct uterine trauma. Arteriovenous malformations of the uterus are rare lesions although it is likely that they have been underreported. The true incidence of uterine AVMs though unknown is significant enough to warrant clinician awareness.
The classical presentation of uterine AVMs is often one of severe uterine bleeding with no obvious cause especially in a woman who has recently given birth. In particular, there should be a high index of suspicion of uterine artery pseudoaneurysm in women presenting with secondary PPH after C-section. ${ }^{16}$ Neglecting to consider the diagnosis of AVM in a woman with vaginal bleeding can cause lethal hemorrhage if curettage is undertaken. However, there is also a recognized potential to over-diagnose uterine AVMs in the postpartum periods. ${ }^{17}$ Many so-called uterine AVMs diagnosed in the early postpartum period spontaneously resolve on follow-up imaging. ${ }^{18}$ This issue has clinical importance because if curettage is not performed for fear of heavy bleeding related to a possible uterine AVM, the patient may undergo preventable blood loss due to the presence of RPOC. It may be reasonable to consider proceeding with D\&C with angiographic backup available if there is a high clinical suspicion for RPOC in a patient with a vascular uterine mass. ${ }^{19}$ Correlation with $\beta$-human chorionic gonadotropin measurements and noninvasive imaging such as transvaginal scanning with color Doppler may be helpful in the treatment of these challenging patients.

Torres first described the gray scale findings of uterine AVM in 1979 as 'multiple structures with a serpentine contour within the myometrium. ${ }^{\prime 20}$ The most common gray scale findings of a uterine AVM are numerous prominent cystic or tubular anechoic areas within the myometrium or less commonly, a myometrial or endometrial mass or prominent parametrial vessels. Grayscale ultrasonography alone may play a role in diagnosis but the features of AVM may overlap with other causes of arteriovenous shunting such as gestational trophoblastic disease, RPOC and subinvolution of the placental bed, which are on the differential for vaginal bleeding in a postpartum patient. Most areas of enhanced myometrial vascularity (EMV) are determined to be a stage in the subinvolution of the placental bed, which resolves over time. These findings are quite common and may cloud the diagnosis of AVM.

The numerous diagnoses that can present with abnormal vaginal bleeding and with sonographic findings similar to uterine AVM, necessitate that clinicians be able to prioritize the appropriate treatment decisions. The addition of color Doppler improves the diagnostic ability of ultrasonography and both can be used not only to diagnose a uterine AVM but also for documenting resolution. Color Doppler shows a mosaic pattern indicating a turbulent flow resulting from the many direct arteriovenous connections that are present (Fig. 8). Pulsed Doppler evaluation will normally reveal a continuous high-velocity flow throughout both the 
systolic and diastolic components of the cardiac cycle, illustrating a typical high velocity, low resistance blood flow pattern (Fig. 9).

The current gold standard method of diagnosis is pelvic angiography (Fig. 14). This invasive procedure not only allows confirmation of the diagnosis, but also helps to identify the leading 'feeder' vessels where embolization may be indicated as a conservative treatment option. ${ }^{21}$ The patient can be asked to give consent for embolization prior to angiography, thereby avoiding the need for a second therapeutic procedure. Additionally, location of the lesion by prior Doppler ultrasound may aid the embolization procedure. Therapeutic intervention of an AVM is now commonly accomplished through uterine artery embolization (UAE) with hysterectomy reserved for refractory cases.

Diagnosis of uterine AVM has traditionally proved difficult. Not all cases of EMV documented by color Doppler represent true cases of AVM, meaning not all cases of documented uterine AVM need aggressive treatment. With spontaneous resolution in the vast majority of patients presenting with vaginal bleeding and signs of AVM on transvaginal ultrasound, clinicians must decide when to proceed with UAE and when to utilize conservative management.

\section{Case 5: Placenta Accreta}

Placenta accreta is defined as a placenta which is abnormally adherent and sometimes invasive to the uterus, due to total or partial lack of the decidua basalis layer. The Nitabuch membrane, a fibrinoid layer that separates the deciduas basalis from the placental villi, is imperfectly

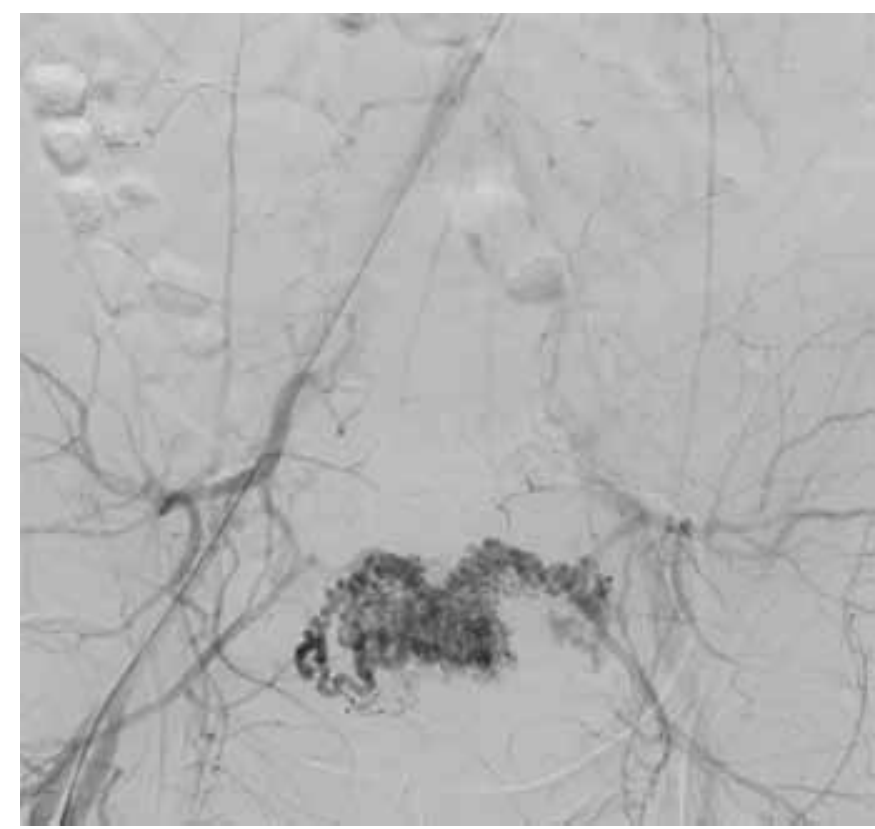

Fig. 14: Pelvic angiography of the patient demonstrated in Figures 7 to 10 . Note tortuous feeder vessels consistent with AVM developed. It is divided into three grades based on histopathology: placenta accreta/vera where the chorionic villi are in contact with, but do not invade the myometrium; placenta increta where the chorionic villi invade the myometrium, and placenta percreta where the chorionic villi invade beyond the whole myometrium, into the uterine serosa and possibly into adjacent organs (especially the bladder). Placenta accreta is the most common placental attachment disorder found in approximately $75 \%$ of all cases of abnormally adherent placentas. $^{22}$

Risk factors for placenta accreta include prior cesarean delivery, placenta previa, prior uterine surgery, prior myomectomy, prior dilation and evacuation, Asherman's syndrome, submucous leiomyomata, maternal age $\geq 35$ years old, multiparity and smoking. Amongst these, prior cesarean section and placenta previa are the two most important risk factors for placenta accreta. ${ }^{23}$ Hence, all patients with prior cesarean delivery and placenta previa should be assessed for ultrasonographic evidence of placenta accreta. Note that in case 5 (Fig. 11) placenta is covering the internal cervical os and could not be demarcated from the uterine wall. Hypoechoic tortuous spaces within the placenta were emphasized with the use of color Doppler (Fig. 12).

In the US, placenta accreta is becoming increasingly common, occurring most often in women who have placenta previa and have had a cesarean delivery in a previous pregnancy. In women who have placenta previa risk increases from about $10 \%$ if they have had one cesarean delivery to more than $60 \%$ if they have had 4 C-sections.

Massive hemorrhage at the time of delivery is the most important clinical issue in cases of placenta accreta. It has now become the most common indication for obstetric/ peripartum hysterectomy. ${ }^{24}$ Gravid hysterectomy is associated with an incidence of maternal mortality of up to $7 \%$, with a $90 \%$ incidence of transfusion, $28 \%$ incidence of postoperative transfusion and a $5 \%$ incidence of ureteral injuries or fistula formation. Other obstetrical complications including preterm birth and intrauterine growth restriction are also increased with this diagnosis. ${ }^{25}$

Placenta accreta is rarely diagnosed antenatally. The antenatal diagnosis of placenta accreta can be suspected by obstetrical history (e.g. history of prior cesarean delivery), ultrasound and/or magnetic resonance imaging (MRI). Unfortunately, even the postpartum diagnosis is controversial. Postpartum histologic examination would require both the placenta and the uterus, including the sample of the entire interface, conditions that are almost never present. If only the placenta is examined histologically, usually the specimen is in pieces, only a 
few placental surfaces are sampled and small areas that might contain myometrial tissue may be missed. So, in cases of clinically suspected placenta accreta, failure to demonstrate adherence of myometrial tissue to the maternal surface of the placenta cannot always be used to the exclude this diagnosis. ${ }^{26}$

Currently, no single diagnostic modality determines the diagnosis of placenta accreta with absolute accuracy; however, sonography remains the primary diagnostic tool and routine ultrasound examination at 18 to 20 weeks gestation affords an ideal opportunity to screen for this disorder. Sonographic findings in the first trimester include an irregular placental-myometrial interface, anechoic placental areas, and low implantation of the gestational sac. ${ }^{27}$ Second and third trimester grayscale sonographic findings include loss of continuity of the uterine wall; presence of multiple vascular lacunae (irregular vascular spaces) within the placenta, giving a 'moth-eaten' or 'Swiss cheese' placental appearance; thinning or loss of normal hypoechoic retroplacental myometrial zone to less than $2 \mathrm{~mm}$ between the placenta and the myometrium; thinning or disruption of the hyperechogenic uterine serosa-bladder interface; the presence of focal mass-like elevations or extensions of placental tissue beyond the uterine serosa. Of these, the presence of intraplacental lacunae was the first criterion to be associated with placenta accreta and it was reported that the larger and more irregular the intraplacental lacunae became, the higher the frequency of placenta accreta (Figs 11 and 12). Since, intraplacental lacunae are associated with adherent placenta, they may be used to predict obstetric complications. ${ }^{28}$ Reduced anterior myometrial thickness (less than $1 \mathrm{~mm}$ ) as measured between the echogenic serosa and the retroplacental vessels is also reported to be as predictive as placental lacunae for placenta accreta (Figs 15 and 16). ${ }^{23}$ Absence

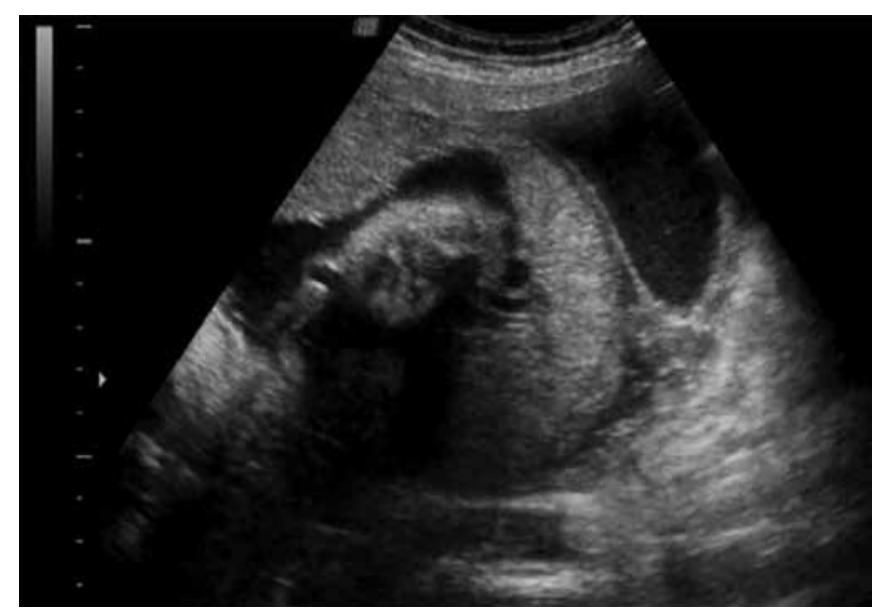

Fig. 15: B mode sonogram demonstrating reduced anterior myometrial thickness (less than $1 \mathrm{~mm}$ ) as measured between the echogenic serosa and the retroplacental vessels of the hypoechoic zone is thought to represent a defect in decidua basalis and adjacent myometrium and has also been seen in normal pregnancies. However, it is one of the more obvious findings at screening evaluation and should prompt a detailed evaluation for other ultrasound markers. ${ }^{29}$ Color and/or power Doppler reveals hypervascularity of the interface between the uterine serosa and the bladder wall (Fig. 17).

Three-dimensional power Doppler may be useful as a complementary technique for the antenatal diagnosis or exclusion of placenta accreta. 'Numerous coherent vessels' detected by three-dimensional power Doppler in the basal view were the best single criterion for the diagnosis of placenta accreta. The depiction of turbulent blood flow in placental lacunae and the presence of low-resistance arterial blood flow in the serosa-bladder interface on color Doppler imaging are highly predictive of accreta. ${ }^{30}$

If the ultrasound findings are not considered definitive or the placenta is located on the posterior wall or to assess possible bladder involvement, MRI can be

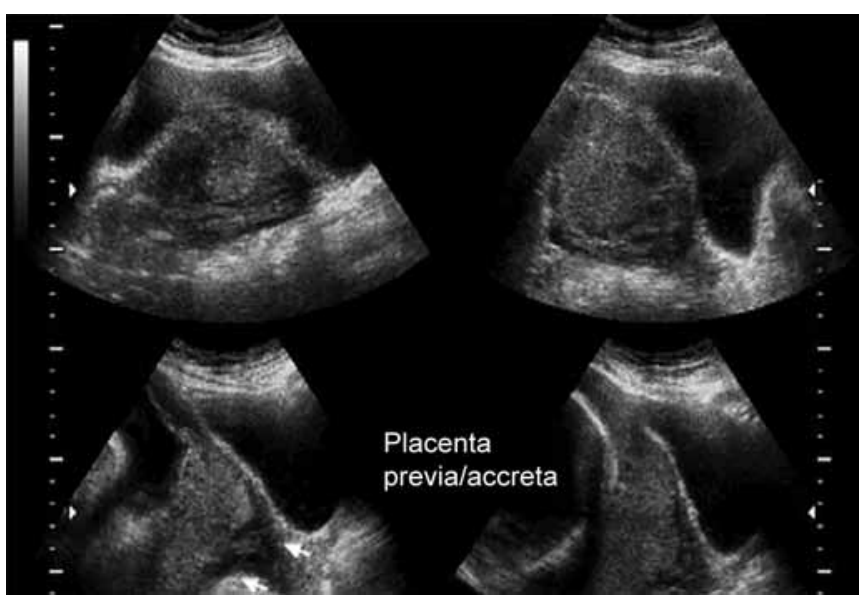

Fig. 16: Three-dimensional ultrasound enables better assessment of the reduced myometrial thickness

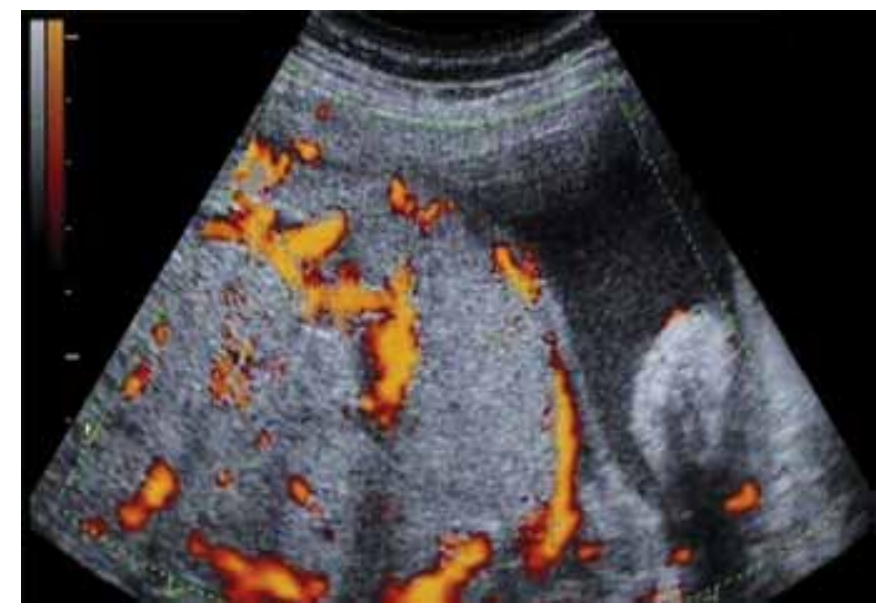

Fig. 17: Power Doppler image of the same patient. Note the presence of hypervascularity of the interface between the uterine serosa and the bladder wall. Sonographic and Doppler findings are suggestive of placenta accreta 
performed using gadolinium contrast intravenously. Magnetic resonance imaging findings suggestive of placenta accreta include placental heterogeneity; mass effect of the placenta into the underlying bladder or extending laterally or posteriorly beyond the normal uterine contour; obliteration of the myometrial zone visible on initial uptake of gadolinium and a beading nodularity within the placenta. ${ }^{31}$ Cystoscopy can be considered in cases where bladder invasion is highly suspected by radiologic studies.

Other than the imaging methods, elevated biochemical markers in maternal serum, such as elevated levels of alpha fetoprotein and human chorionic gonadotropin within the triple screening test have been reported to be associated with an increased risk of placenta accreta. Though the mechanism is unclear, abnormality of the placental-uterine interface that may lead to leakage into the maternal circulation may explain this increase. ${ }^{32}$

During delivery, the disorder is suspected if:

- The placenta has not been delivered within 30 minutes of the infant's delivery

- Attempts at manual removal cannot create a plane of separation

- Placental traction causes large volume hemorrhage.

Clearly, clinical judgment at delivery is necessary in

these cases. Placenta accreta, increta and percreta remain among the greatest treatment challenges in modern obstetrics. Massive hemorrhage can easily accompany these conditions. Often patients exit the operating room in an extremely critical condition. The most important component of successful management of invasive placental conditions remains preparation.

If placenta accreta is suspected, appropriate counseling and preoperative multidisciplinary preparation should be made. Accurate prenatal identification of affected pregnancies allows optimal management because timing and site of delivery, availability of blood products and recruitment of a skilled anesthesia, surgical, urology and interventional radiology team can be arranged in advance. ${ }^{33}$ In the past, conservative hysterectomy with the placenta left in situ was a definitive treatment for accreta. Recently, preoperative catheterization of uterine/hypogastric arteries for potential postpartum embolization and/or balloon inflation has been reported to play a major role in minimizing the risk of bleeding intraoperatively. ${ }^{34}$

The best gestational age for delivery of a patient with placenta accreta is unknown, but most authors recommend 36 to 37 weeks with some consideration for the potential benefit of fetal lung maturity amniocentesis. C-section is usually planned at 36 to 37 weeks to minimize the risk of spontaneous labor. Detailed maternal counseling including that concerning the desire for future fertility can be taken into consideration during delivery planning. This may be the treatment of choice if the patient desires future fertility. Prenatal diagnosis of placental accreta also permits the family to be better prepared for a potential life-threatening obstetric complications.

There are three potential approaches to managing of the placenta accreta after delivery of the baby:

- Attempt at delivery of placenta: In many cases, as accreta cannot be confirmed antenatally with $100 \%$ accuracy by radiologic studies, an attempt at spontaneous placental delivery is made. Creation of a bladder flap may be beneficial in case a hysterectomy is later necessary. Uterine incision should be made away from the placenta, which is 'mapped' by preoperative ultrasound. If spontaneous placental delivery fails, the operator must decide if either manual placental removal in pieces or hysterectomy is the next intervention. Hysterectomy may be necessary if uterine bleeding cannot be controlled, hopefully before massive blood loss and cardiovascular instability. Given most bleeding is from the lower part of the uterus, usually total hysterectomy including the cervix is necessary. ${ }^{35}$

- Planned hysterectomy: If the diagnosis is highly suspected by history and radiologic studies and the woman does not desire further fertility (e.g. had requested tubal ligation), it might be prudent to deliver the neonate and proceed with hysterectomy while the placenta remains attached. ${ }^{36}$ In these controlled situations, maternal morbidity of gravid hysterectomy may be decreased, but fertility is lost.

- Expectant or medical management: The placenta is left in situ, with either no therapy or, most commonly, methotrexate therapy. Medical management should be considered only when the woman wants to preserve her fertility and no active uterine bleeding is present. The cord is ligated and the uterus closed with the placenta in situ. Antibiotics prophylaxis is suggested given the risk of infection and short-term uterotonics for PPH prevention. Follow-up is done with serial ultrasounds (up to daily) and quantitative hCG to monitor involution and decrease in placental vascularity. ${ }^{37}$ Over $90 \%$ of the reports state successful outcomes, with future pregnancies and avoidance of gravid hysterectomy. In some cases, hysterectomy may be needed for late-occurring hemorrhage.

\section{REFERENCES}

1. American College of Obstetricians and Gynecologists. ACOG Practice Bulletin: Clinical Management Guidelines for Obstetricians-Gynecologists Number 76, October 2006: Postpartum hemorrhage. Obstet Gynecol 2006;108(4):1039-1047. 
2. Berg CJ, Chang J, Callaghan WM, Whitehead SJ. Pregnancyrelated mortality in the United States, 1991-1997. Obstet Gynecol 2003;101(2):289-296.

3. Tamizian O, Arulkumaran S. Management of postpartum haemorrhage (Chapter 14). In: The management of labour. Arulkumaran S, Penna LK, Bhaskar Rao K, editors. 2nd ed. New Delhi, India: Orient Longman Pvt. Limited 2005. p. 209-229.

4. Arias F. Practical Guide to High Risk Pregnancy and Delivery. 2nd ed. Salt Lake City, UT: Mosby Inc.,US 1993, ISBN: 10: 080160057X, p. 433-451.

5. King PA, Duthie SJ, Dong ZG, Ma HK. Secondary postpartum hemorrhage. Aust NZ J Obstet Gynaecol 1989;29(4):394-398.

6. Uchil D. Complications of the puerperium (Chapter 28). In: The management of labour. Arulkumaran S, Penna LK, Bhaskar Rao K, editors. 2nd ed. New Delhi, India: Orient Longman Pvt. Limited 2005. p. 419-434.

7. Mulic-Lutvica A. Donald school textbook of ultrasound in obstetrics and gynecology (Chapter 32). In: Postpartum ultrasound physiology of normal puerperium. Kurjak A, Chervenak FA, editors. New Delhi: Jaypee Brothers Medical Publishers 2011; ISBN: 978-93-5025-259-8. p. 521-525.

8. Baskett TF. Complications of the third stage of labour. In: essential management of obstetrical emergencies. Baskett TF, editor. 3rd ed. Bristol, UK: Clinical Press; 1999. p. 196-201.

9. Georgiou M, Penna LK. The third stage of labor (Chapter 13). In: the management of labour. Arulkumaran S, Penna LK, Bhaskar Rao K, editors. 2nd ed. New Delhi, India: Orient Longman Pvt Limited 2005. p. 195.

10. Das B, Clark S. A textbook of postpartum hemorrhage: a comprehensive guide to evaluation, management and surgical intervention (Chapter 44). In: Sepsis and postpartum hemorrhage. Christopher B-Lynch, Keith LG, Lalonde AB, Karoshi M, editors. New Delhi, India: Jaypee Brothers Medical Publishers 2006;ISBN: 978-0-9552282-3-0. p. 404.

11. Urmanikar A, Urmanikar S, Parmar D. World clinics: obstetrics and gynaecology-postpartum hemorrhage. In: postpartum sepsis. Arora M, Walavalkar R, editors. New Delhi, India: Jaypee Brothers Medical Publishers 2012; ISBN: 978-93-5090-424-4. p. 247-248.

12. Johnson IR, McEwan A, James D. Obstetrics and gynaecology vade-mecum, Chapter 13, postnatal problems. Boca Raton, FL: CRC Press 2000; ISBN: 0340 69274. p. 164.

13. Kelly SM, Belli AM, Campbell S. Arteriovenous malformation of the uterus associated with secondary postpartum hemorrhage. Ultrasound Obstet Gynecol 2003;21(6):602-605.

14. Fielding JR, Brown DL, Thurmond AS. Postpartum complications-Arteriovenous Malformations. In: Gynecologic Imaging. Fielding JR, Brown DL, Thurmond AS, editors. Philadelphia, USA: Elsevier Saunders Inc., ISBN-13: 978-14377-1575-0. p. 602.

15. Vogelzang RL, Nemcek AA Jr, Skrtic Z, Gorrell J, Jurain JR. Uterine arteriovenous malformations: primary treatment with therapeutic embolization. J Vasc Interv Radiol 1991; 2(4):517-522.

16. Ganguli S, Stecker MS, Pyne D, Baum RA, Fan CM. Uterine artery embolization in the treatment of postpartum uterine hemorrhage. J Vasc Interv Radiol 2011;22(2):169-176.

17. Mungen E. Vascular abnormalities of the uterus: have we recently overdiagnosed them? Ultrasound Obstet Gynecol 2003;21(6):529-531.
18. Brown DL. Pelvic ultrasound in the postabortion and postpartum patient. Ultrasound Q 2005;21(1):27-37.

19. Rufener SL, Adusumilli S, Weadock WJ, Caoili E. Sonography of uterine abnormalities in postpartum and postabortion patients. J Ultrasound Med 2008;27(3):343-348.

20. Torres WE, Sones PJ Jr, Thames FM. Ultrasound appearance of a pelvic arteriovenous malformation. J Clin Ultrasound 1979;7(5):383-385.

21. Forrsman L, Lungberg J, Schersten T. Conservative treatment of uterine arteriovenous fistula. Acta Obstet Gynecol Scand 1982;61(1):85-87.

22. Miller DA, Chollet JA, Goodwin TM. Clinical risk factors for placenta previa-placenta accreta. Am J Obstet Gynecol 1997;177(1):210-214.

23. Baughman WC, Corteville J, Shah RR. Placenta accretaspectrum of US and MR imaging findings. Radio Graphics 2008;28(7):1905-1916.

24. O'Brien JM, Barton JR, Donaldson ES. The management of placenta percreta- conservative and operative strategies. Am J Obstet Gynecol 1996;175(6):1632-1638.

25. Gielchinsky Y, Mankuta D, Rojansky N, Laufer N, Gielchinsky, Ezra Y. Perinatal outcome of pregnancies complicated by placenta accreta. Obstet Gynecol 2004;104(3):527-530.

26. Jacques SM, Qureshi F, Trent VS, Ramirez NC. Placenta accreta-mild cases diagnoses by placental examination. Int J Gynecol Pathol 1996;15(1):28-33.

27. Ballas J, Pretorius D, Hull AD, Resnik, Ramos GA. Identifying sonographic markers for placenta accreta in the first trimester, J Ultrasound Med 2012;31(11):1835-1841.

28. Yang JI, Lim YK, Kim HS, Chang KH, Lee JP, Ryu HS. Sonographic findings of placental lacunae and the prediction of adherent placenta in women with placenta previa totalis and prior cesarean section. Ultrasound Obstet Gynecol 2006;28 (2):178-182.

29. Hoffman-Tretin JC, Koenigsberg M, Rabin A. Placenta accreta-additional sonographic observations. J Ultrasound Med 1992;11(1):29-34.

30. Chou MM, Ho ES, Lu F, Lee YH. Prenatal diagnosis of placenta previa/accreta with color Doppler ultrasound. Ultrasound Obstet Gynecol 1992;2(4):293-296.

31. Levine D, Hulka CA, Ludmir J, Li W, Edelman RR. Placenta accreta-evaluation with color Doppler US, power Doppler US and MR imaging. Radiol 1997;205(3):773-776.

32. Zelop C, Nadel A, Frigoletto FD, Pauker S, MacMillan M, Benacerraf BR. Placenta accreta/percreta/increta- a cause of elevated maternal serum alpha-fetoprotein. Obstet Gynecol 1992;80(4):693-694

33. Usta IM, Hobeika EM, Musa AA, Gabriel GE, Nassar AH. Placenta previa-accreta: risk factors and complications. Am J Obstet Gynecol 2005;193(3 pt 2):1045-1049.

34. Tan CH, Tay KH, Sheah K. Perioperative endovascular internal iliac artery occlusion balloon placement in management of placenta accreta. Am J Roentgenol 2007;189(5):1158-1163.

35. Hudon L, Belfort MA, Broome DR. Diagnosis and management of placenta percreta: a review. Obstet Gynecol Surv 1988;53(8):509-517.

36. American College of Obstetricians and Gynecologists. Placenta accreta. ACOG Committee Opinion No. 266, January 2002.

37. Hundley AF, Lee-Parrotz A. Managing placenta accreta. OBG Management 2002;14(8):18-33. 


\section{SELF-ASSESSMENT QUIZ}

1. A 23-year-old Caucasian female delivered a $9 \mathrm{lb}$ healthy baby 30 minutes back at 37 weeks gestation. Even though the labor is prolonged, the baby and placenta were delivered spontaneously without application of forceps. Even after placental delivery, the patient appears to bleed continuously. She has lost approximately 1.5 liters of blood. IV Ringer's lactate is administered. Her temperature is $36.7^{\circ} \mathrm{C}\left(98^{\circ} \mathrm{F}\right)$, blood pressure is $100 / 60 \mathrm{~mm} \mathrm{Hg}$, pulse is $102 / \mathrm{min}$, and respirations are $18 / \mathrm{min}$. Which of the following is the most appropriate next step in the management of this patient?
A. Intravenous oxytocin
B. Pelvic examination
C. Pelvic ultrasound
D. Bimanual uterine massage
E. Uterine artery ligation

2. You are called to the maternity ward to see a 20 -year-old primiparous patient who delivered a healthy baby $\mathbf{2}$ days ago. She had a normal vaginal delivery and placenta was delivered spontaneously. Now she complains of bloody vaginal discharge with no other signs. On examination you notice a sweetish odor, and bloody discharge along with some small blood clots on the introitus and vaginal walls. Sterile pelvic examination reveals a soft and non-tender uterus. Her vitals are: temperature of $37^{\circ} \mathrm{C}$, blood pressure of $120 / 80 \mathrm{~mm} \mathrm{Hg}$, respiratory rate of $16 / \mathrm{min}$ and pulse rate of $76 /$ min. Initial laboratory tests reveal WBC of 10,000 with predominant granulocytes. What is the most appropriate next step in management?
A. Reassurance
B. Perform pelvic ultrasound
C. Give oral antibiotics
D. Order urinalysis
E. Culture of discharge

3. A 34-year-old G1P0 at 39 weeks' gestation comes to the labor and delivery unit because of contractions. Her prenatal course was significant for anemia in the third trimester. Examination shows the cervix to be $6 \mathrm{~cm}$ dilated and the fetus in footling breech presentation. External fetal monitoring shows the fetal heart rate to be in the 140 seconds and reactive. A cesarean section is performed. Which of the following risk factors places this patient at the greatest risk for developing postpartum endometritis?
A. Anemia
B. Cesarean section
C. External fetal monitoring
D. Intact membranes
E. Socioeconomic status

4. A 24-year-old white female delivered a healthy baby vaginally at 36 weeks' gestation. She had prolonged premature rupture of membranes and on delivery, mid forceps application was required. On the 2nd postpartum day her vital signs were blood pressure of $120 / 55 \mathrm{~mm} \mathrm{Hg}$, temperature of $38.5^{\circ} \mathrm{C}$, pulse rate of $85 / \mathrm{min}$ and respiratory rate of $18 \mathrm{~min}$. On bimanual examination, uterine tenderness and foul smelling lochia are noted. Urinalysis reveals nothing remarkable. Pelvic ultrasound demonstrates thickened and hypervascular endometrium with moderate vascular impedance (RI 0.55, PI 1.34). There is no evidence of residual products of conception. Which pathogen is most likely responsible for this patient's condition?

A. Listeria monocytogenes

B. Group B Streptococcus

C. Escherichia coli

D. Enterococci

E. Anaerobes

5. You were called to see a 30 -year-old multiparous woman on the 3rd day postpartum. Her labor lasted 20 hours and ended with a vaginal delivery with episiotomy. Placenta could not be evacuated spontaneously so manual delivery was needed. This morning she complains of suprapubic tenderness and fever of $39^{\circ} \mathrm{C}$. She also states that she could not breast-feed because her 'nipples are tender'. On examination, uterine tenderness is noted. Pelvic ultrasound detected hyperechogenic thickened endometrium $(14 \mathrm{~mm})$ with scattered peripheral vascularization. No placental remnants are found in the uterine cavity. Pulsed Doppler assessment revealed low velocity-moderate vascular impedance blood flow signals (RI 0.58, PI 1.58). Her nipples are cracked without redness or warmth of the breasts. The rest of the examination is without abnormal findings. Urinalysis was performed and revealed nothing abnormal. What is the most likely diagnosis in this patient?
A. Endometritis
B. Atelectasis 

C. Episiotomy wound infection
D. Puerperal mastitis
E. Pelvic thrombophlebitis

6. A 33-year-old G3P3 delivered her third baby at full term through spontaneous vaginal delivery 3 weeks earlier. She now presents with two episodes of heavy vaginal bleeding. Her obstetrical history was uneventful. Upon examination, she was afebrile and hemodynamically stable with a hemoglobin $(\mathrm{Hb})$ level of $12.4 \mathrm{~g} / \mathrm{dl}$. Vaginal examination showed a small amount of blood at the external orifice of the uterus, but no active bleed was observed. Transabdominal ultrasound of the pelvis showed a bulky uterus with an endometrial thickness of $1.5 \mathrm{~cm}$. What is the next best step?
A. Hysteroscopy under anesthesia
B. Abdominal and pelvic CT
C. Uterine artery angiogram
D. Endometrial biopsy and histopathological examination
E. Human chorionic gonadotropin (hCG) level
F. Uterine artery embolization

7. A 28-year-old G2P2 presented with excessive vaginal bleeding. She had undergone an elective cesarean section 19 days ago for suspected macrosomia. She was apparently asymptomatic for 15 days postoperation. She later developed excessive vaginal bleeding, high grade fever and was readmitted. On abdominal examination, the C-section scar was closed with evidence of normal healing. On pelvic examination the uterus was bulky and the cervical os was closed. Her hemoglobin level was $9.8 \mathrm{~g} / \mathrm{dl}$ and serum beta-hCG was $43 \mathrm{IU} / \mathrm{ml}$. Transvaginal ultrasonography with color Doppler showed a heterogeneous mass $3.0 \times 4.5 \mathrm{~cm}$ size with prominent vessels measuring 1.5 to $2.0 \mathrm{~cm}$ mean diameter. Pulsed Doppler waveform analysis revealed high velocity arterial and venous blood flow signals. What is the most likely diagnosis?
A. Retained products of conception
B. Endometritis
C. Gestational trophoblastic disease
D. Arteriovenous malformation

8. A 20-year-old G2P1 with history of one missed abortion, presented with moderate episode of vaginal bleeding for the last 3 days. She had a full-term spontaneous normal vaginal delivery 6 weeks back. Her first pregnancy 3 years ago ended as missed abortion for which dilatation and evacuation was performed. At the time of admission her vitals were stable, she was not bleeding, and mild pallor was present. Transvaginal and color Doppler ultrasound revealed an area of increased vascularity in the anterior uterine wall near fundus confined to the subendometrial region. The lesion measured $4.0 \times 3.0 \mathrm{~cm}$. A diagnosis of uterine arteriovenous malformation (AVM) was made. What is the definitive management in this patient, considering she desires fertility?
A. Dilation and curettage
B. Methylergometrine
C. Hysterectomy
D. Angiography and uterine artery embolization
E. Sequential ethinylestradiol and medroxyprogesterone acetate therapy
F. Antibiotics

9. A 28-year-old patient G2P2 who delivered a $3580 \mathrm{gm}$ male fetus by cesarean section a month ago presented with postpartum hemorrhage. She underwent a dilation and curettage for suspected retained products of conception. The patient presented with recurrent severe bleeding after a week and a uterine AVM was considered. The most accurate test to diagnose a uterine AVM is?
A. Hysteroscopy
B. Laparoscopy
C. Pelvic angiogram
D. Transvaginal ultrasound
E. Abdominal/pelvic CT
F. Magnetic resonance imaging

10. Which of the following is a contraindication for uterine artery embolization?
A. Uterine AVM
B. Renal insufficiency
C. Placenta accreta
D. Uterine fibroid
E. Ovarian cyst

Correct Answers:
1. B;
2. A; 3. B;
4. E;
5. A;
6. E; 7. D;
8. D;
9. C;
10. B 